\title{
Removal of Malachite Green by Stishovite-TiO Nanocomposite and Stishovite Clay- A Comparative Study
}

\author{
V. VENKATESWARAN ${ }^{\mathrm{a}}$, V. T. PRIYA ${ }^{\mathrm{b}}$ and P. BALASUBRAMANIYAM ${ }^{\mathrm{c}}$
}

${ }^{a}$ Sree Saraswathi Thyagaraja College, Pollachi, India

${ }^{\mathrm{b}}$ Department of Chemistry, Erode Arts \& Science College (Autonomous), Erode, India

${ }^{\mathrm{c}}$ Erode Sengundhar Engineering College, Thudupathi, India

vvprinceeac@gmail.com

Received 21 October 2012 / Accepted 12 November 2012

\begin{abstract}
The removal of malachite green by adsorption on stishovite- $\mathrm{TiO}_{2}$ nanocomposite as well as on stishovite clay under optimized conditions has been studied. The effect of several parameters such as adsorbent dose, contact time, initial concentration, $\mathrm{pH}$, temperature has been evaluated. The application of pseudo first order, pseudo second order, Elkovich kinetic model and intraparticle diffusion model have been calculated. The adsorption on both the clay and nanocomposite followed pseudo second order kinetics. The equilibrium data fitted well with Langmuir and Freundlich models. Thermodynamic parameters such as free energy change $\left(\Delta \mathrm{G}^{0}\right)$, enthalpy change $\left(\Delta \mathrm{H}^{0}\right)$ and entropy change $\left(\Delta S^{0}\right)$ indicate the adsorption process to be endothermic and spontaneous. The surface morphology of the adsorbents have been analysed using the scanning electron microscope (SEM). The study revealed that nanocomposite is more effective than clay in removing malachite green by adsorption.
\end{abstract}

Keywords: Nanocomposite, Malachite green, Adsorption isotherm, Thermodynamics of adsorption, Kinetics

\section{Introduction}

A wide range of technologies and methods like coagulation, oxidation, electrochemical, ion-exchange, biodegradation and ultra-filtration have been discovered and adopted to remove the excessive discharges of colourants from petrochemical, textile, leather-making, pharmaceutical as well as food and beverage industries. However all these are not comparable to adsorption technique in term of efficiency, operating cost, process flexibility and ease of operation ${ }^{1-3}$. Further these methods are inefficient and incompetent because these dyes are stable towards light, oxidizing agents and aerobic digestion and are also highly soluble in aqueous media. A comprehensive investigation shows that adsorption technique was the most appropriate and efficient one $e^{4,5}$. 
Malachite green, a triphenylmethane dye, is most widely used for coloring purposes in many industries ${ }^{6,7}$. This dye when present in water bodies even at low concentrations affects the aquatic life and causes detrimental effects on liver, gills, kidneys, intestine and gonads ${ }^{8}$. In humans, it may cause irritation to the gastrointestinal tract. The present study is aimed at comparing the effectiveness of both Stishovite- $\mathrm{TiO}_{2}$ nanocomposite and stishovite clay in removing malachite green by adsorption.

\section{Experimental}

Stishovite (3g) was allowed to swell in $15 \mathrm{~mL}$ of water-free alcohol and stirred for 2 hours at $25{ }^{\circ} \mathrm{C}$ to get a uniform suspension. At the same time, the titanium dioxide $(\mathbf{3 g})$ was dispersed into water-free alcohol $(15 \mathrm{~mL})$. Then the diluted titanium dioxide was slowly added into the suspension of stishovite and stirred for a further 5 hours at $25{ }^{\circ} \mathrm{C}$. Finally, $5 \mathrm{~mL}$ alcohol mixed with $0.2 \mathrm{~mL}$ deionized water was slowly added. The stirring was continued for another 5 hours at $25{ }^{\circ} \mathrm{C}$ and the resulting suspension was kept overnight in a vacuum oven for 6 hours at $80^{\circ} \mathrm{C}$.

\section{Absorbate solution}

A stock solution $(1000 \mathrm{mg} / \mathrm{L})$ of malachite green, the adsorbate used in this study, was prepared using doubly distilled water. Various solutions with different initial concentrations were prepared by diluting the stock dye solution.

\section{Characterization of adsorbent}

Physicochemical characteristics of the adsorbents were studied as per the standard testing methods. The XRD pattern of pure stishovite clay (Figure 1) and that of stishovite- $\mathrm{TiO}_{2}$ nanocomposite (Figure 2) show characteristic peaks at $28^{\circ}$ and $30^{\circ}$ which the presence of stishovite- $\mathrm{TiO}_{2}$ phase in the nanocomposite. The surface morphology of the adsorbents were visualized via scanning electron microscopy (SEM) (Figure $3 \& 4$ ). The diameter of the composite range was $50 \mu \mathrm{m}$.

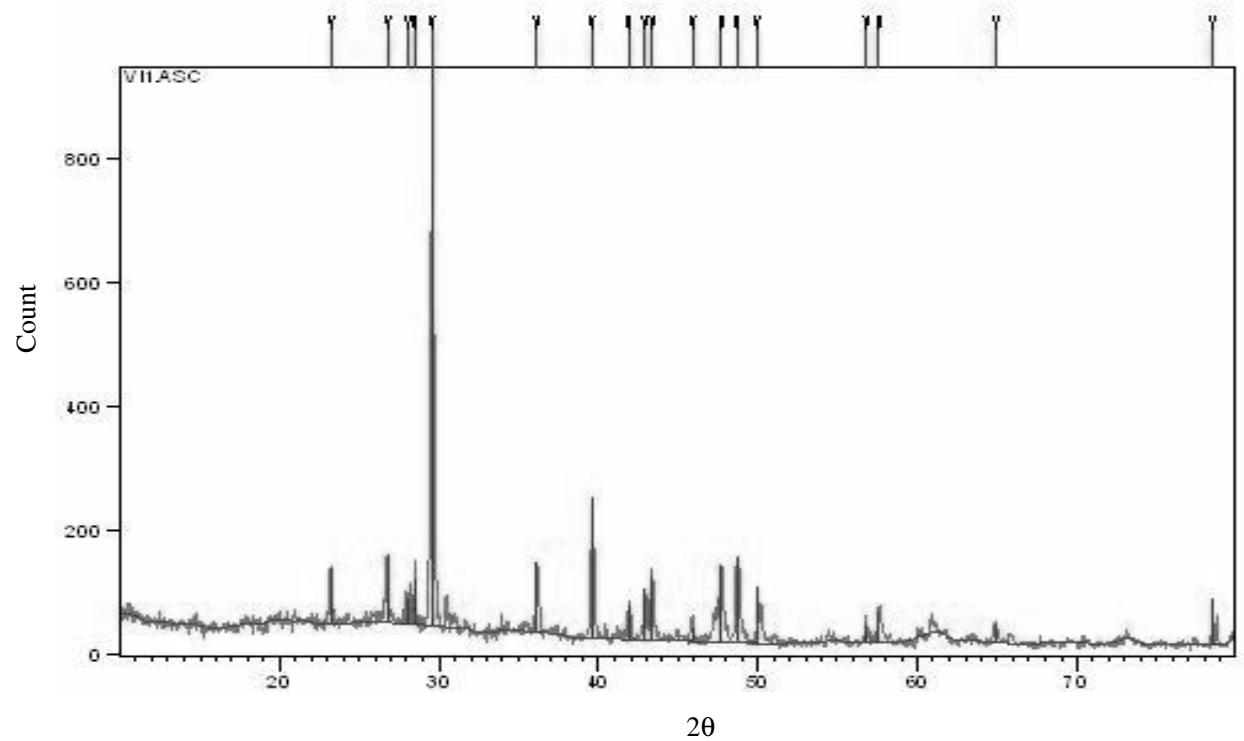

Figure 1. XRD analysis of stishovite 


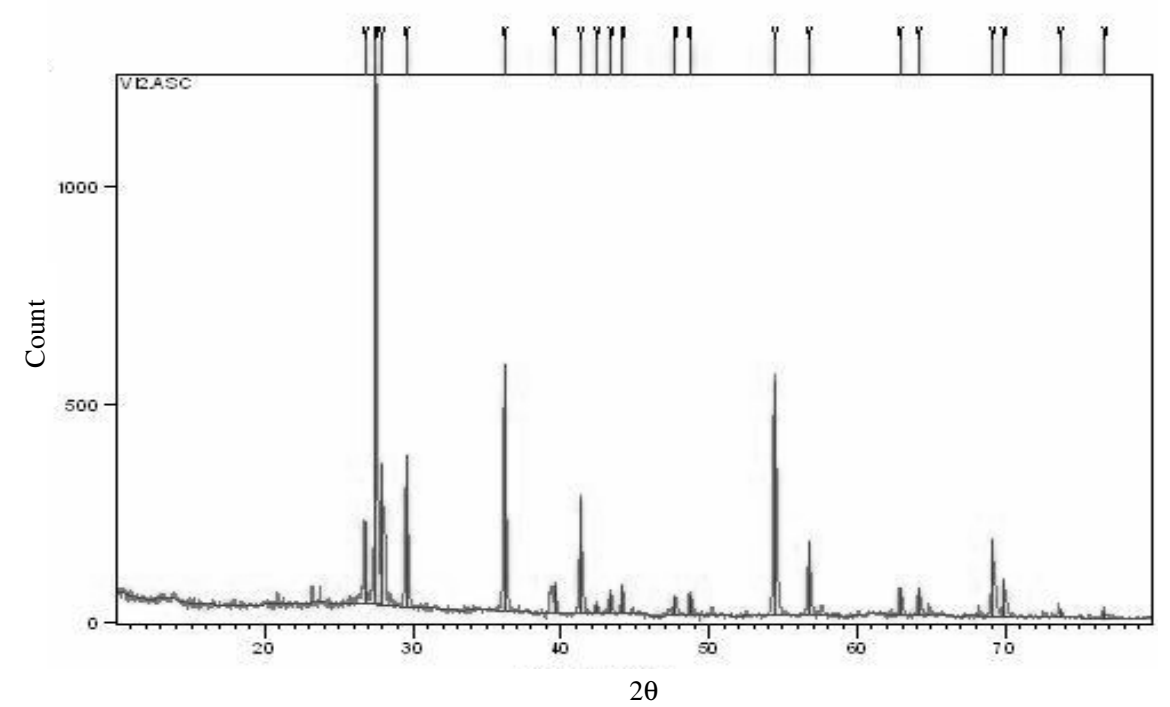

Figure 2. XRD analysis of stishovite- $\mathrm{TiO}_{2}$ composite

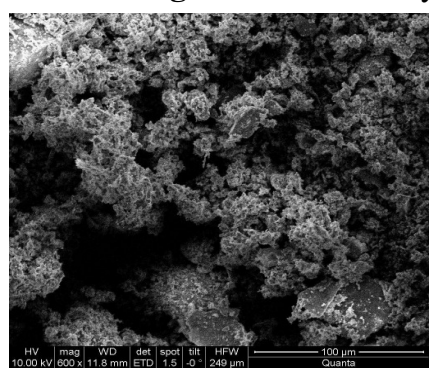

Figure 3. SEM of stishovite

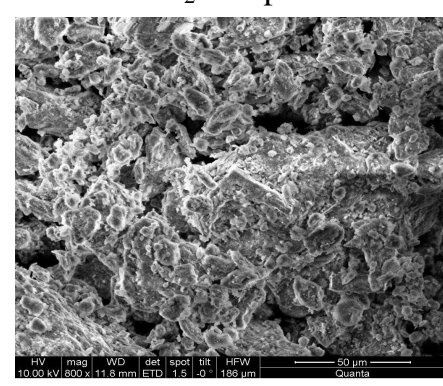

Figure 4. $\mathrm{SEM}$ of stishovite - $\mathrm{TiO}_{2}$ nanocomposite

\section{Batch adsorption experiments}

Entire batch mode experiments were carried out by taking $50 \mathrm{~mL}$ of the dye solution and a known amount of the adsorbent in a $100 \mathrm{~mL}$ conical flask. The flasks were agitated for predetermined time intervals in a thermostat attached with a shaker at the desired temperatures ( $303 \mathrm{~K}$ to $311 \mathrm{~K})$ and then the adsorbent and adsorbate were separated by filtration. Studies on the effects of agitation time, $\mathrm{pH}$, initial dye concentration, adsorbent dose and temperature were carried out by using known amount of adsorbent and $50 \mathrm{~mL}$ of dye solution of different concentrations. Dye solution $(50 \mathrm{~mL})$ with different amounts of adsorbent was taken to study the effect of adsorbent dosage.

\section{Results and Discussion}

\section{Effect of contact time and initial dye concentration}

The experimental results of adsorptions at various concentrations (10, 20, 30 and $40 \mathrm{mg} / \mathrm{L})$ on both nanocomposite and clay are shown in Figure 5. It was observed that percent adsorption increased with increase in initial dye concentration showing that the adsorption is highly dependent on initial concentration of dye. At lower concentration, the ratio of the initial 
number of dye molecules to the available surface area is low. Subsequently, the fractional adsorption becomes independent of initial concentration. However, at high concentration the available sites of adsorption become fewer and hence the percentage removal of dye is dependent upon initial concentration ${ }^{9,10}$. Equilibrium was established after $90 \mathrm{~min}$ for all concentrations. The curves are single, smooth and continuous, leading to saturation, suggesting the possible monolayer coverage of the dye on the adsorbent surfaces ${ }^{11}$.
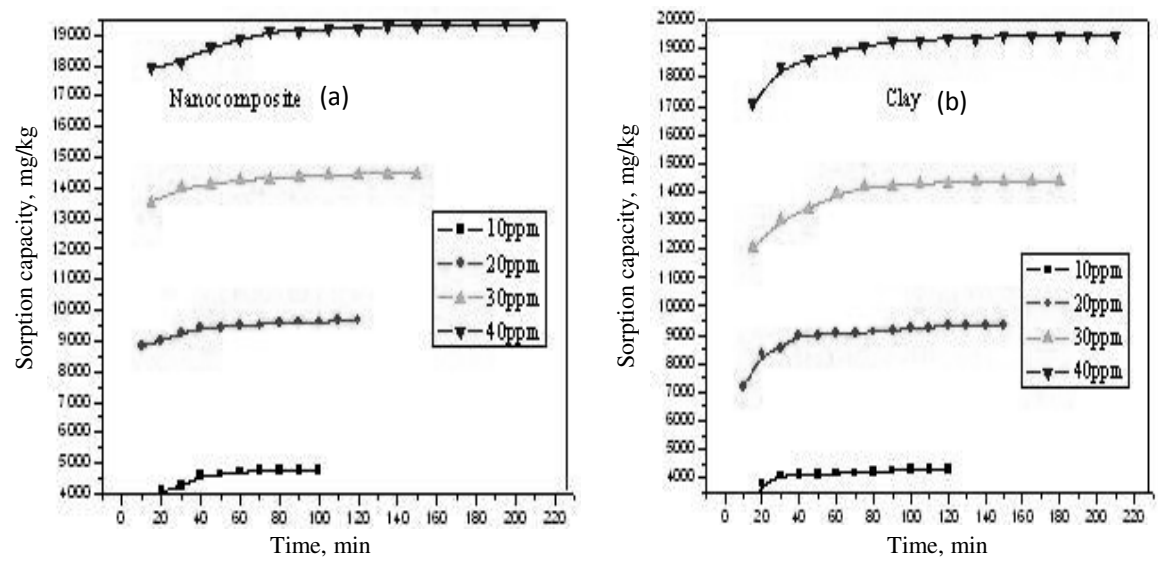

Figure 5. Effect of contact time and initial dye concentration a) Nanocomposite; b) Clay

\section{Effect of adsorbent dose}

The adsorption of the malachite green was studied by varying the adsorbent dose $(100-1000 \mathrm{mg} / 50 \mathrm{~mL})$ for $10-40 \mathrm{mg} / \mathrm{L}$ of dye concentrations. With both nanocomposite and clay the percentage of adsorption increased with increase in concentration of the adsorbent (Figure 6). This was attributed to increase in adsorbent surface area and the availability of more adsorption sites ${ }^{9,10}$.
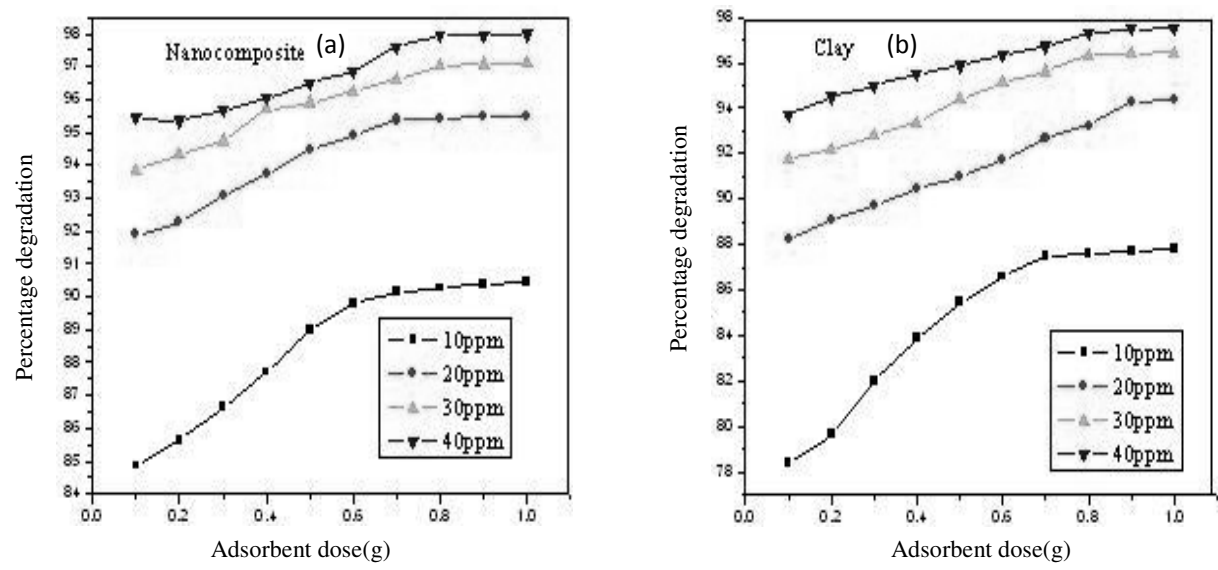

\section{Effect of $p H$}

Figure 6. Effect of adsorbent dose a) Nanocomposite; b) Clay

Adsorption experiments were carried out at various $\mathrm{pH}$ values ranging from 3 to 11 , maintaining the $\mathrm{pH}$ by adding required amount of dilute hydrochloric acid and sodium hydroxide 
solutions. A pH meter calibrated with 4.0 and 9.0 buffers was used with both nanocomposite and clay. The data showed that the maximum dye removal had occurred in basic medium and with increase in $\mathrm{pH}$ the sorption capacity also increased (Figure 7).
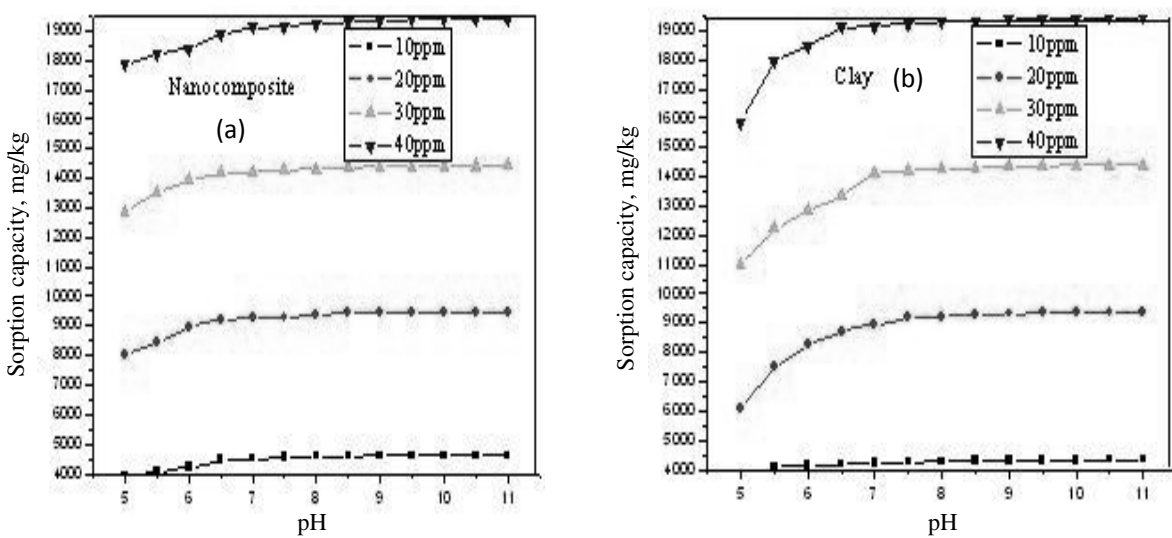

Figure 7. Effect of $\mathrm{pH}$ a) Nanocomposite; b) Clay

\section{Effect of temperature}

The results of studies on the effect of temperature on the removal of malachite green by the nanocomposite and clay are shown Figure 8. The amount of basic dye adsorbed increased with increasing temperature from $303 \mathrm{~K}$ to $311 \mathrm{~K}$ indicating the adsorption process to be endothermic. This may be attributed to the increase in rate of diffusion of adsorbate molecules across the external boundary layer and internal pores of adsorbent particle with increase in temperature.
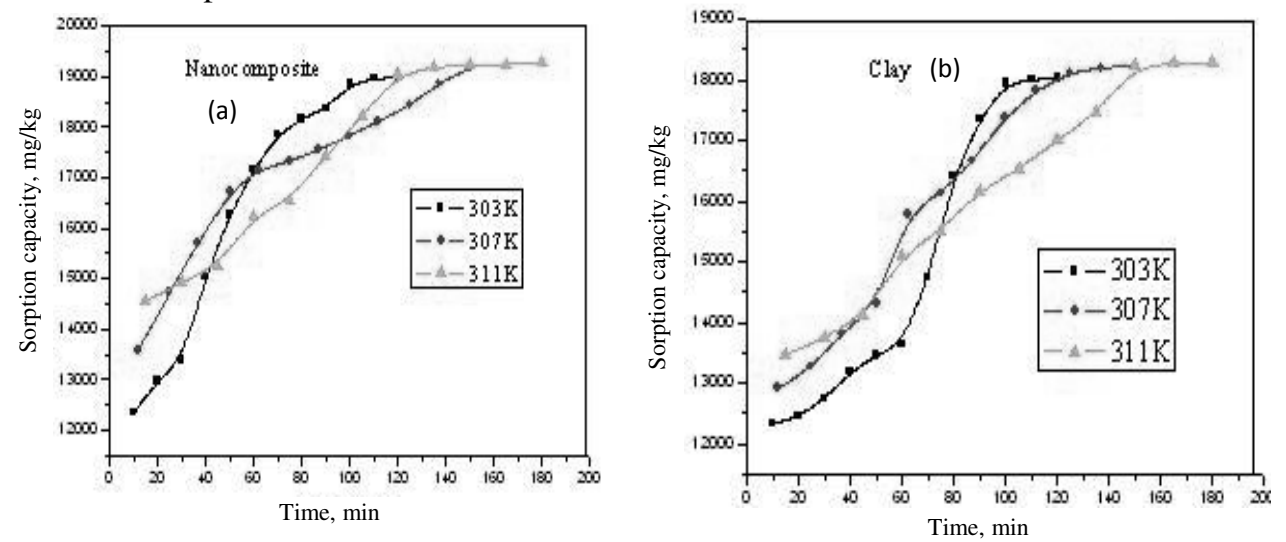

Figure 8. Effect of temperature a) Nanocomposite; b) Clay

\section{Adsorption isotherm}

The experimental data were analyzed according to the linear form of the widely used Langmuir $^{13}$ and Freundlich ${ }^{14}$ isotherms. The Langmuir isotherm in its usual form is represented as

$$
C_{e} / q_{e}=1 / b q_{0}+C_{e} / q_{0}
$$


Where $\mathrm{C}_{\mathrm{e}}$ is the equilibrium concentration $(\mathrm{mg} / \mathrm{L}), \mathrm{q}_{\mathrm{e}}$ is the amount adsorbed at equilibrium $(\mathrm{mg} / \mathrm{g})$ and $\mathrm{Q}_{0}$ and $\mathrm{b}$ are Langmuir constants related to adsorption efficiency and energy of adsorption respectively. The linear plots of $\mathrm{C}_{\mathrm{e}} / \mathrm{q}_{\mathrm{e}}$ versus $\mathrm{C}_{\mathrm{e}}$ suggest the applicability of the Langmuir isotherm for the adsorption of malachite green by both the adsorbants and representative plots are given in Figure 9. The values of $\mathrm{Q}^{0}$ and $\mathrm{b}$ were determined from the slope and intercepts of the plots. To confirm the favorability of the adsorption process, the separation factor, $R_{L}=1 /\left(1+b C_{0}\right)$ has been calculated and the values were found to be between 0 and 1 (Table1) which confirms that the adsorption process is favourable ${ }^{15}$.

The Freundlich isotherm can be represented in its linear form as

$$
\log q_{e}=\log K_{f}+1 / n \log C_{e}
$$

Where $\mathrm{q}_{\mathrm{e}}$ is the amount adsorbed at equilibrium $(\mathrm{mg} / \mathrm{g}) ; \mathrm{C}_{\mathrm{e}}$ is the equilibrium concentration of the adsorbate and $\mathrm{K}$ and $\mathrm{n}$ are constants incorporating all factors affecting the adsorption capacity and intensity of adsorption respectively. Linear plots of $\log \mathrm{q}_{\mathrm{e}}$ versus $\log \mathrm{C}_{\mathrm{e}}$ show that the adsorption of dye follows the Freundlich isotherm and representative plots are given in Figure 10 and the data in Table 2.
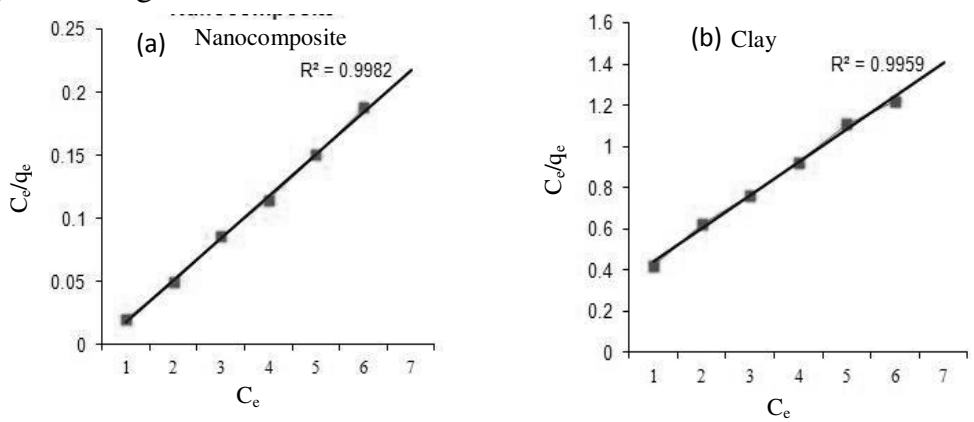

Figure 9. Langmuir model a) Nanocomposite; b) Clay
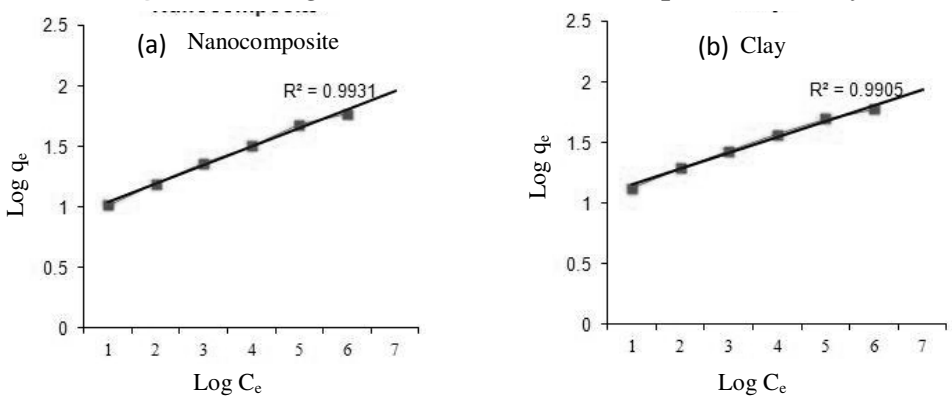

Figure 10. Freundlich model a) Nanocomposite; b) Clay

Table 1. The values of Langmuir constant $\mathrm{Q}^{0}$ and $\mathrm{b}$ in addition to $\mathrm{R}_{\mathrm{L}}$

\begin{tabular}{ccccccccc}
\hline Concentration & \multicolumn{3}{c}{ Stishovite $-\mathrm{TiO}_{2}$ nanocomposite } & \multicolumn{5}{c}{ Stishovite Clay } \\
\cline { 2 - 8 } of dye, $\mathrm{mg} / \mathrm{L}$ & $\mathrm{R}_{\mathrm{L}}$ & $\mathrm{b}$ & $\mathrm{Q}^{\circ} \mathrm{mg} / \mathrm{g}$ & $\mathrm{R}^{2}$ & $\mathrm{R}_{\mathrm{L}}$ & $\mathrm{b}$ & $\mathrm{Q}^{\circ} \mathrm{mg} / \mathrm{g}$ & $\mathrm{R}^{2}$ \\
\hline 20 & 0.9953 & & & & 0.7716 & & & \\
40 & 0.9906 & & & & 0.6281 & & & \\
60 & 0.9860 & 0.000236 & 65.189 & 0.9982 & 0.5296 & 0.0148 & 8.2236 & 0.9959 \\
80 & 0.9815 & & & & 0.4578 & & & \\
100 & 0.9769 & & & & 0.4032 & & & \\
120 & 0.9724 & & & & 0.3602 & & & \\
\hline
\end{tabular}


Table 2. The values of Freundlich constant $\mathrm{K}_{\mathrm{f}}$ and $\mathrm{n}$

\begin{tabular}{cccc}
\hline Adsorbent & $\mathrm{K}_{\mathrm{f}} \mathrm{L} / \mathrm{mg}$ & $\mathrm{n} \mathrm{mg} / \mathrm{g}$ & $\mathrm{R}^{2}$ \\
\hline Stishovite $-\mathrm{TiO}_{2}$ nanocomposite & 4.265 & 1.461 & 0.9931 \\
Stishovite Clay & 33.884 & 0.126 & 0.9905 \\
\hline
\end{tabular}

\section{Kinetics of adsorption}

In order to investigate the mechanism of adsorption of malachite green by the clay and nanocomposite the following three kinetic models were considered.

\section{Pseudo first order kinetic model}

The integrated linear form of this model proposed by Lagergren is

$$
\log \left(q_{e}-q_{t}\right)=\log q_{e}-\left(k_{1} / 2.303\right) t
$$

Where $\mathrm{q}_{\mathrm{e}}$ is the amount of dye adsorbed at equilibrium $(\mathrm{mg} / \mathrm{g})$ and $\mathrm{q}_{\mathrm{t}}$ is the amount of dye adsorbed $(\mathrm{mg} / \mathrm{g})$ at time $\mathrm{t}, \mathrm{k}_{1}$ is the first order rate constant $\left(\mathrm{min}^{-1}\right)$ and $\mathrm{t}$ is time $(\mathrm{m})$. Hence a linear trace is expected between the two parameters $\log \left(\mathrm{q}_{\mathrm{e}}-\mathrm{q}_{\mathrm{t}}\right)$ and $\mathrm{t}$, in case the adsorption follows first order kinetics. It is observed that the data does not fit in to first order equation.

\section{Pseudo second order kinetics}

The adsorption may also be described by pseudo second order kinetic model, the linearised form of which is

$$
t / q_{t}=1 / k_{2} q_{e}^{2}+1 / q_{e} \times t
$$

Where $\mathrm{k}_{2}$ is the second order rate constant $(\mathrm{g} / \mathrm{mg} \min )$. A plot of $\mathrm{t} / \mathrm{q}_{\mathrm{t}} v s$. $\mathrm{t}$ should give a linear relationship if the adsorption follows second order. $\mathrm{q}_{\mathrm{e}}$ and $\mathrm{k}_{2}$ can be calculated from the slope and intercept of the plot. Figure 11 shows the pseudo second order plot for the adsorption of malachite green on the nanocomposite and clay at various initial dye concentrations. The linear plots obtained clearly show that the adsorption process follow pseudo second order kinetics.
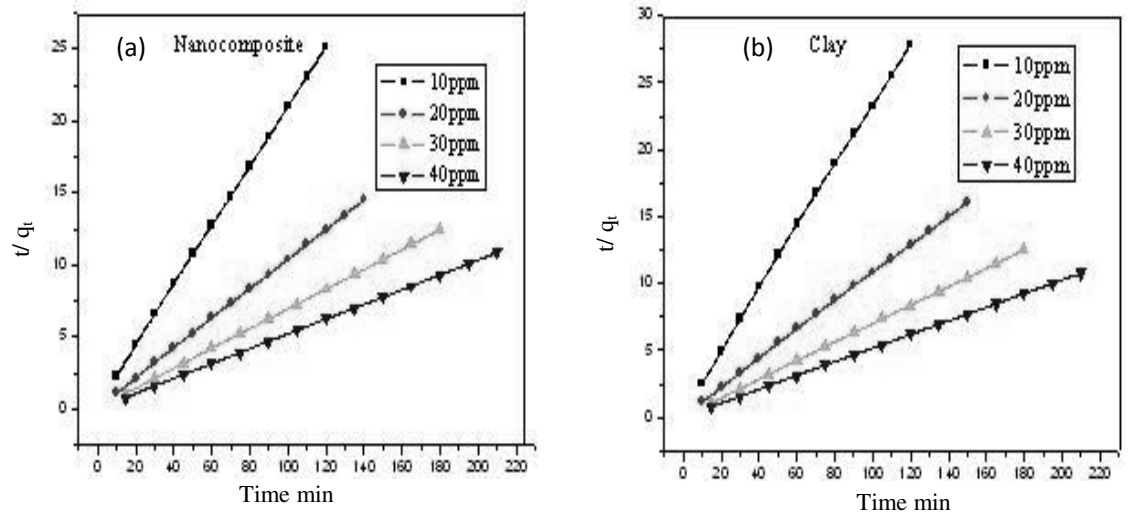

Figure 11. Pseudo second order kinetics a) Nanocomposite; b) Clay

\section{Elkovich kinetic model}

The Elkovich equation is mainly applicable for chemisorption and often valid for systems with heterogeneous adsorbing surfaces ${ }^{16}$. The Elkovich model is generally expressed in its integrated form as 


$$
Q_{t}=(1 / b) \ln (a b)+(1 / b) \ln t
$$

Where ' $a$ ' is the initial adsorption rate $(\mathrm{mg} / \mathrm{g} \mathrm{min})$ and ' $b$ ' is related to the extent of surface coverage and the activation energy for chemisorption $(\mathrm{g} / \mathrm{mg})$. A plot of $\mathrm{q}_{\mathrm{t}} v s$. $\ln \mathrm{t}$ is a straight line with a slope of $1 / \mathrm{b}$ and an intercept $\log 1 / \mathrm{b} \ln (\mathrm{ab})$ with good correlation coefficients showing that adsorption of malachite green over the whole range of variables studied followed the Elkovich model suggesting chemisorptions (Figure 12).
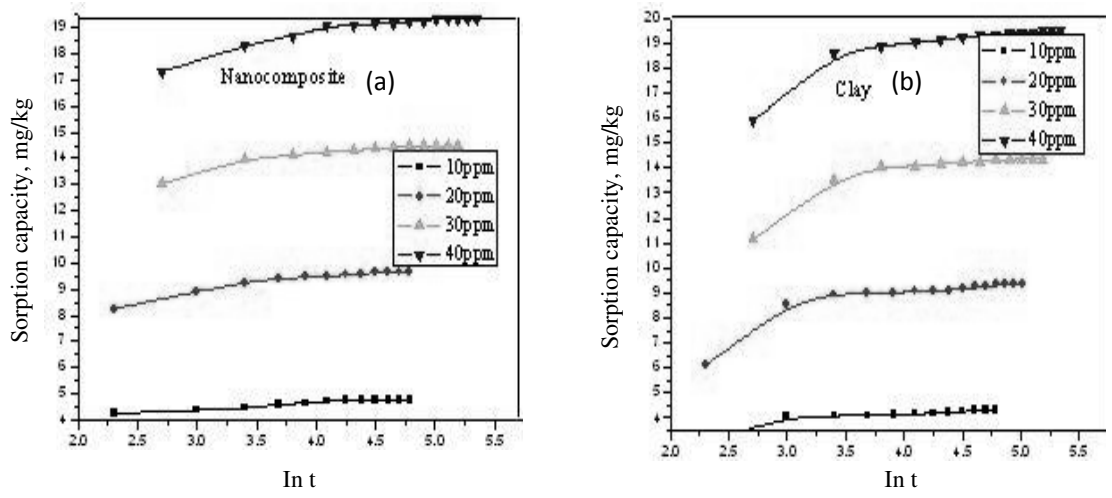

Figure 12. Elkovich kinetic model a) Nanocomposite; b) Clay

\section{Intraparticle diffusion study}

In the batch mode adsorption process, initial adsorption occurs on the surface of the adsorbent. In addition, there is a possibility of the absorbate to diffuse into the interior pores of the adsorbent. Weber and Morris ${ }^{17}$ suggested the following kinetic model to investigate whether the adsorption is intra particle diffusion or not. The relationship may be given as

$$
q_{t}=K_{i d} t_{1 / 2}+C
$$

Where $\mathrm{K}_{\mathrm{id}}$ is the intraparticle diffusion rate constant and is calculated by plotting $\mathrm{q}_{\mathrm{t}} v s$. $t_{1 / 2}$ and the results are given in Figure 13. The linear portion of the plot for does not pass through the origin. This deviation from the origin may be due to the variation of mass transfer in the initial and final stages of adsorption ${ }^{15}$. Such a deviation from the origin indicates that pore diffusion is the only controlling step and not the film diffusion.
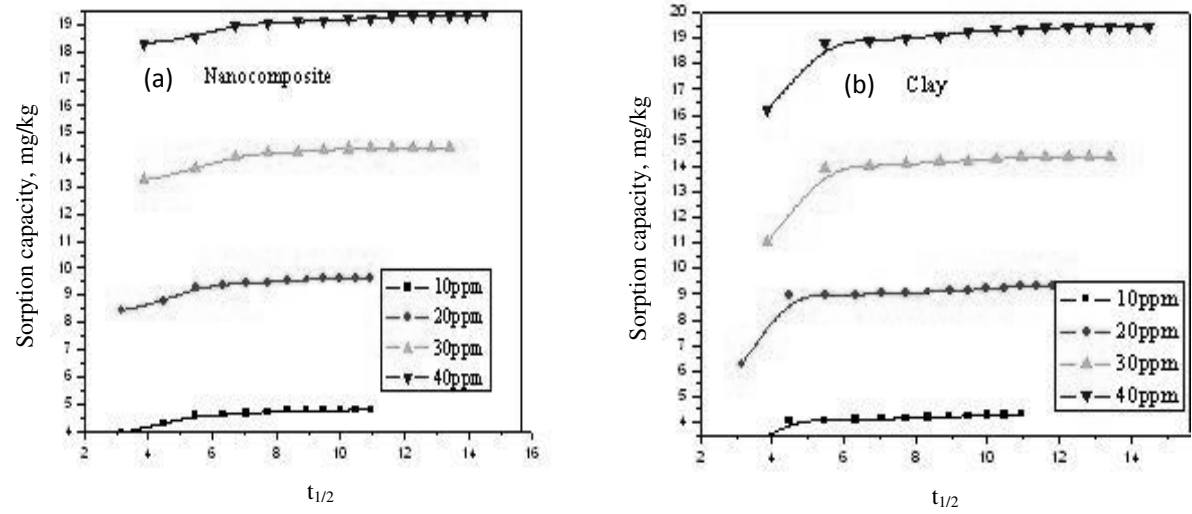

Figure 13. Intraparticle diffusion study a) Nanocomposite; b) Clay 
Where $K_{i d}$ is the intraparticle diffusion rate constant and is calculated by plotting $\mathrm{q}_{\mathrm{t}} v s$. $t_{1 / 2}$ and the results are given in Figure 13. The linear portion of the plot for does not pass through the origin. This deviation from the origin may be due to the variation of mass transfer in the initial and final stages of adsorption ${ }^{15}$. Such a deviation from the origin indicates that pore diffusion is the only controlling step and not the film diffusion.

\section{Thermodynamic of adsorption}

Thermodynamic parameters like $\Delta \mathrm{H}^{0}$ and $\Delta \mathrm{S}^{0}$ were evaluated using Van't Hoff's equation;

$$
\ln K_{c}=\Delta S^{0} / R-\Delta H^{0} / R T
$$

Where $\mathrm{K}_{\mathrm{c}}$ is the Langmuir equilibrium constant, $\Delta \mathrm{H}^{0}$ and $\Delta \mathrm{S}^{0}$ are the standard enthalpy and entropy changes of adsorption respectively and their values are calculated from the slopes and intercepts respectively of the linear plot of $\ln \mathrm{K}_{\mathrm{c}} v s .1 / \mathrm{T}$. The free energy of specific adsorption $\Delta \mathrm{G}^{0}(\mathrm{Kj} / \mathrm{mol})$ is calculated using

$$
\Delta G^{0}=\Delta H^{0}-T \Delta S^{0}
$$

The thermodynamic parameters calculated are given in Table 3. Negative free energy and positive entropy of adsorption indicates that the adsorption process is favourable and spontaneous in. The endothermic nature of adsorption is confirmed by the positive $\Delta \mathrm{H}^{0}$ value.

Table 3. Thermodynamic parameters for adsorption of Malachite green on Stishovite $-\mathrm{TiO}_{2}$ NC \& stishovite Clay

\begin{tabular}{cccccc}
\hline \multirow{2}{*}{ Adsorbent } & \multicolumn{3}{c}{$-\Delta \mathrm{G}^{0} \mathrm{Kj} / \mathrm{mol}$} & \multirow{2}{*}{$\Delta \mathrm{S}^{0} \mathrm{Kj} / \mathrm{mol}$} & \begin{tabular}{c}
$\Delta \mathrm{H}^{0}$ \\
\cline { 2 - 4 } $\mathrm{Kj} / \mathrm{mol}$
\end{tabular} \\
\hline $\begin{array}{c}\text { Stishovite - } \mathrm{TiO}_{2} \\
\text { nanocomposite }\end{array}$ & 8.149 & 8.255 & 8.362 & 2.660 & 8.945 \\
Stishovite Clay & 8.248 & 8.356 & 8.463 & 2.693 & 8.862 \\
\hline
\end{tabular}

\section{Desorption studies}

Desorption studies with acetic acid revealed that the regeneration of adsorbent was not satisfactory, which confirms the chemisorptive nature of adsorption.

\section{Conclusion}

The present investigation showed that stishovite- $\mathrm{TiO}_{2}$ nanocomposite and stishovite clay can be used as adsorbent for removal of malachite green. The amount of dye adsorbed varied with initial dye concentration, adsorbent dose, $\mathrm{Ph}$ and temperature. Removal of dye by both nanocomposite and clay was found to obey both Langmuir and Freundlich adsorption models. The adsorption process followed pseudo second order kinetics. This has been further supported by Elkovich chemisorptive kinetic model. Desorption studies reveal that no satisfactory desorption taking place confirming chemisorptive nature of adsorption. Evaluation of thermodynamic parameters showed the process to be endothermic and spontaneous. Intra particle diffusion studies reveal that pore diffusion play a major role. The study reveals that stishovite- $\mathrm{TiO}_{2}$ nanocomposite is more efficient than the natural stishovite clay in removing the malachite green.

\section{Acknowledgment}

The authors are thankful to UGC for the financial support. 


\section{References}

1. Shi B, Li G, Wang D, Feng C and Tang H, J Hazard Mater., 2007, 143(1-2), 567-574.

2. Fathima N N, Aravindhan R, Rao J R and Nair B U, Chemosphere, 2008, 70(6), 1146-1151.

3. Shen Z M, Wu D, Yang J, Yuan T, Wang W H and Jia J P, J Hazard Mater., 2006, 131(1-3), 90-97.

4. Ruthven D M, Principles of Adsorption and Desorption Processes, John Willey and Sons, New York, 1984.

5. Suzuki M, Fundamentals of Adsorption IV, Kodansha, Tokyo, 1993.

6. Gupta V K, Rastogi A, Saini V K and Jain N, J Colloid Interf Sci., 2006, 296(1), 59-63.

7. Daneshvar N, Ayazloo M, Khataee A R and Pourhassan M, Bioresour Technol., 2007, 98(6), 1176-1182.

8. Srivastava S, Sinha R and Roy D, Aquat Toxicol., 2004, 66(3), 319-329.

9. Namasivayam C, Muniasamy N, Gayathri K, Rani M and Renganathan K, Biores Technol., 1996, 57(1), 37-43.

10. Namasivayam C and Yamuna R T, Environ Pollut., 1995, 89(1),.1-7.

11. Arivoli S, Sundaravadivelu M and Elango K P, Environ Sci Indian J., 2007, 2, 167.

12. Norrozi B, Sorial G A, Bahrami H and Arami. M, J Hazard Mater., 2007, B139, 167-174.

13. Langmuir I, J Am Chem Soc., 1918, 40(9), 1361-1403.

14. Freundlich H, Phys Chemie., 1906, 57, 384.

15. Aravind V and Elango K P, Indian J Chem Technol., 2006, 13, 476.

16. Ozcan A S, Erdem B and Ozcan A, Colloid Surface A., 2005, 266(1-3), 73-81.

17. Weber W J and Morris J C, Water Poll Res., 1963, 2, 231. 